\title{
MELHORAMENTO GENÉTICO DAS CULTIVARES DE MILHO CMS 47 E BR 5039 (SÃO VICENTE) NA REGIÃO MEIO-NORTE DO BRASIL
}

\author{
MILTON JOSÉ CARDOSO ${ }^{1}$, HÉLIO WILSON LEMOS DE CARVALHO ${ }^{2}$, MARIA DE LOURDES \\ DA SILVA LEAL ${ }^{2}$, MANOEL XAVIER DOS SANTOS ${ }^{3}$

\begin{abstract}
${ }^{1}$ Embrapa Meio-Norte. Caixa Postal 01, CEP. 64.006-220 Teresina, PI. E-mail: milton@cpamn.embrapa.br (autor para correspondência)

${ }^{2}$ Embrapa Tabuleiros Costeiros. Caixa Postal 44, CEP. 49.001-970 Aracaju, SE.E-mail: helio@cpatc.embrapa.br

${ }^{3}$ Embrapa Milho e Sorgo. Caixa Postal 151, CEP. 35.701-970 Sete Lagoas, MG.E-mail: xavier@cnpms.embrapa.br
\end{abstract}

Revista Brasileira de Milho e Sorgo, v.2, n.3, p.88-96, 2003

\begin{abstract}
RESUMO - No ano agrícola de 2000/2001, a variedade sintética CMS 47 e a variedade BR 5039 foram submetidas ao ciclo I de seleção entre e dentro de progênies de meios-irmãos, na região Meio-Norte do Brasil, visando elevar a freqüência de alelos favoráveis e obter estimativas de parâmetros genéticos e fenotípicos. Foram avaliadas 196 progênies de cada material, em látice simples 14 x 14, com recombinação das progênies superiores, dentro do mesmo ano agrícola, de modo a se obter um ciclo por ano. Para o peso de espiga, a variedade sintética CMS 47 apresentou maior variabilidade que a variedade BR 5039, refletida em um maior componente da variância genética aditiva. $O$ ganho médio esperado com a seleção entre $\mathrm{e}$ dentro de progênies de meios-irmãos também expressa essa variabilidade, foi 5,63\% na variedade sintética CMS 47 e $0,72 \%$, na variedade BR 5039. A magnitude da interação progênies $\mathrm{x}$ locais evidenciou a importância de se avaliar as progênies em mais de um local, para melhorar a eficiência do processo seletivo e obter estimativas mais consistentes dos componentes da variância.
\end{abstract}

Palavras-chave: Zea mays, melhoramento intrapopulacional, ganho genético.

\section{GENETIC IMPROVEMENT OF CORN CULTIVARS CMS 47 AND BR 5039 (SÃO VICENTE) IN MID-NORTHERN BRAZIL}

\begin{abstract}
In the agricultural year of 2000/2001 the corn varieties CMS 47 sintetic and the BR 5039 were submitted to one cycle of half-sib family selection in the Brazilian MidNorth Region, to elevate the favorable alleles frequency and to obtain estimates of the genetic and phenotypic parameters. In the same agricultural year, for obtaining one cycle by year, 196 families were evaluated in a $14 \times 14$ simple lattice experimental design, with recombination of the selected families. For ear weight, the CMS 47 sintetic variety had higher variability than the BR 5039, contemplated with a larger component of the additive genetic variance. The expected genetic gain with the half-sib family selection also expressed that variability, being $5.63 \%$ for the CMS 47 and $0.72 \%$, for the BR 5039. The magnitude of the family $x$ environment interaction points out the importance of evaluating the families in more than one location, to improve the efficiency of the selective process and to obtain more consistent estimates of the variance components.
\end{abstract}

Key Words: Zea mays, improvement intrapopulation, genetic gain. 
A região Meio-Norte do Brasil apresenta diversidade de solo e clima em toda a sua extensão e grande variação no nível sócioecômico, detectando-se áreas onde predomina uma agricultura tradicional, com problemas agravantes de produtividade, e áreas que se desenvolveram, transformandose em pólos de desenvolvimento, com larga utilização de insumos modernos de produção. Nesse contexto, a utilização de variedades melhoradas, com bom nível de adaptação e portadoras de atributos agronômicos desejáveis, em substituição às variedades tradicionais, proporcionará melhoria na produtividade da cultura do milho. Cardoso et al. (1997) identificaram variedades promissoras para a região Meio-Norte, selecionando, entre outras, a CMS 47, de porte baixo e ciclo superprecoce, de extrema importância para as áreas de domínio do semi-árido localizadas no Estado do Piauí, e a variedade BR 5039 (São Vicente), de porte normal e ciclo semitardio, para as demais áreas dessa região.

Essas cultivares demonstraram possuir suficiente variabilidade genética ao serem submetidas ao ciclo inicial de seleção entre e dentro de progênies de meios-irmãos, nessa região (Cardoso et al., 2001). Neste trabalho, as altas médias de produtividades das progênies, associadas às altas magnitudes dos parâmetros genéticos, expressaram o grande potencial dessas cultivares em um programa de melhoramento, justificando o desenvolvimento de novos ciclos de seleção.

Entre os esquemas de seleção intrapopulacional, o método de seleção entre e dentro de progênies de meios-irmãos tem-se mostrado eficiente, por ser de fácil execução e permitir o melhoramento genético de populações de milho em taxas elevadas, pela possibilidade de realização de dois ciclos/ano.

Trabalhos da literatura apontam a existência de quantidade suficientemente grande da variância genética aditiva em populações de milho, sendo a mesma também mostrada como a principal componente da variância genética do caráter produção de grãos. Ramalho (1977) efetuou um levantamento das estimativas obtidas de trabalhos com progênies de meios-irmãos, totalizando 30 populações. $\mathrm{O}$ valor médio encontrado foi de 320,0 ( $\left.\mathrm{g} \mathrm{planta}^{-1}\right)^{2}$ para a variância aditiva, com amplitude de $41,0\left(\text { g planta }^{-1}\right)^{2}$ a 758,0 $\left(\mathrm{g}_{\text {planta }}{ }^{-1}\right)^{2}$. Outro levantamento envolvendo 58 testes de progênies de meios-irmãos foi efetuado por Vencovsky et al. (1986), citados por Bigoto (1988), encontrando-se, para a variância genética aditiva, uma amplitude de $41,0\left(\mathrm{~g} \mathrm{planta}^{-1}\right)^{2}$ a 753,0 $\left(\text { g planta }^{-1}\right)^{2}$ e uma média de 309, 0 (g plan$\left.\mathrm{ta}^{-1}\right)^{2}$. Deve-se ressaltar que as estimativas relatadas nesses levantamentos estão superestimadas, pois a avaliação das progênies, em grande parte, foi realizada em apenas um local e não foi possível isolar a variância genética da interação progênies x locais. Trabalhos posteriores geralmente vêm confirmando esses valores dentro dos intervalos citados, para a variância genética aditiva, apesar de, em muitos deles, as progênies terem sido avaliadas em dois e três locais, estando, portanto, menos influenciada pela interação progênies x locais (Aguiar, 1986; Pacheco, 1987; Carvalho et al., 2000a, 2000b e 2000c). Em todos esses casos, os autores consideraram as populações como potencialmente promissoras, para o caráter produção de grãos.

Os objetivos deste trabalho foram estimar os parâmetros genéticos da característica peso de espigas, após a realização de mais um ciclo de seleção entre e dentro de progênies de meios-irmãos, nas cultivares de milho CMS 47 e BR 5039.

\section{Material e Métodos}

O material genético compreendem uma variedade sintética e uma variedade de milho, a CMS 47 e a BR 5039, respectivamente. A variedade sintética CMS 47 tem como características principais a superprecocidade, baixa altura de planta e de 
inserção da primeira espiga e tipo de grão semiduro. A variedade BR 5039 apresenta ciclo semitardio, altura normal de planta e de espiga, bom empalhamento e tipo de grão semiduro.

Após a realização do primeiro ciclo de seleção entre e dentro de progênies de meios-irmãos, no ano agrícola de 1999/2000 (Cardoso et al., 2001), foram selecionadas novas 196 progênies de meios-irmãos, de cada um desses materiais, obedecendo-se aos critérios de competitividade, uniformidade para as alturas de planta e de espiga, bom empalhamento e tipo de grãos semiduros, de coloração amarelo-laranja. Essas progênies foram avaliadas em blocos ao acaso, com duas repetições, realizando-se as avaliações nos municípios de Teresina e Parnaíba, PI, no ano agrícola de 2000/ 2001. Foram utilizadas as variedades Asa Branca e BR 106 como testemunhas, nos ensaios com progênies de meios-irmãos da variedade sintética CMS 47 e da variedade BR 5039, respectivamente. Essas testemunhas foram escolhidas pelo fato de apresentaram bom desempenho produtivo na região (Cardoso et al., 1997). Dentro de cada ensaio, essas testemunhas foram colocadas sistematicamente a cada quatorze parcelas. Cada parcela constou de uma fileira de 5,0 $\mathrm{m}$ de comprimento, espaçadas de $0,80 \mathrm{~m}$ e $0,40 \mathrm{~m}$ entre covas, dentro das fileiras. Foram colocadas três sementes por cova, deixando-se, após o desbaste, duas plantas por cova. Após a realização dos ensaios, foi praticada uma intensidade de seleção de $10 \%$ entre as progênies. As progênies selecionadas foram recombinadas em lotes isolados de despendoamento, onde foram selecionadas 196 novas progênies, correspondendo a uma intensidade de seleção de $10 \%$ dentro das progênies, no mesmo ano agrícola. Nos campos de recombinação, foram utilizadas três fileiras femininas e uma masculina; as fileiras femininas e a masculina tiveram $25 \mathrm{~m}$ de comprimento, espaçadas de $0,90 \mathrm{~m}$ e $0,50 \mathrm{~m}$ entre covas, dentro das fileiras.
Foram colocadas duas sementes por cova, totalizando 100 plantas/fileira. Todos os ensaios e campos de recombinação receberam uma adubação de acordo com os resultados das análises de solo de cada área experimental e da exigência da cultura.

Não foi feita a correção para o estande, em razão de o estande médio observado (23,7 plantas por parcela) ter se aproximado do estande proposto (24 plantas por parcela). Realizou-se, inicialmente, a análise de variância por local, obedecendo ao modelo em blocos ao acaso. Posteriormente, procedeu-se à análise de variância conjunta, obedecendo ao critério de homogeneidade dos quadrados médios residuais. Os quadrados médios das análises de variância conjuntas foram ajustados para o nível de indivíduos, obtendo-se, assim, todas as estimativas nesse nível e expressas em (g planta $\left.{ }^{-1}\right)^{2}$ (Vencovsky, $1978)$. As estimativas da variância aditiva $\left(\sigma^{2}{ }_{\mathrm{A}}\right)$, da variância fenotípica nas próprias plantas $\left(\sigma_{\mathrm{F}}^{2}\right)$ e entre médias de progênies $\left(\sigma_{\mathrm{F}}^{2}\right)$, dos coeficientes de herdabilidade no sentido restrito ao nível de médias de progênies $\left(\mathrm{h}^{2}{ }_{\mathrm{m}}\right)$ e de plantas $\left(\mathrm{h}^{2}\right)$ foram obtidas segundo Vencovsky \& Barriga (1992), pelas seguintes expressões:

$\left(\sigma_{\mathrm{A}}^{2}\right)=4\left(\sigma_{\mathrm{p}}^{2}\right)$

$\left(\sigma_{\mathrm{f}}^{2}\right)=\sigma_{\mathrm{p}}^{2}+\sigma_{\mathrm{pxl}}^{2}+\sigma_{\mathrm{e}}^{2}+\sigma_{\mathrm{d}}^{2}$,

$\left(\sigma_{\mathrm{F}}^{2}\right)=\sigma_{\mathrm{p}}^{2}+\sigma_{\mathrm{e}}^{2} / \mathrm{r}+\sigma_{\mathrm{d}}^{2} / \mathrm{Nr}$,

$\mathrm{h}_{\mathrm{m}=}^{2} \sigma_{\mathrm{p}}^{2} /\left(\sigma_{\mathrm{F}}^{2}\right) \mathrm{e}$,

$\mathrm{h}^{2}=\sigma_{\mathrm{A}}^{2} / \sigma_{\mathrm{F}}^{2}$.

O índice de variação $b$ foi determinado pela relação $\mathrm{CVg} / \mathrm{Cve}$, em que $\mathrm{CVg}$ é o coeficiente de variação genético, e Cve o coeficiente ambiental.

O progresso esperado, quando se utiliza a seleção entre e dentro de progênies de meios-irmãos, dentro do mesmo ano agrícola , foi estimado pela fórmula:

$\mathrm{Gs}=\mathrm{K}_{1} \cdot \sigma_{\mathrm{p} /}^{2}\left(\sigma_{\mathrm{F}}^{2}\right)+\mathrm{K}_{2} \cdot(3 / 8) \sigma_{\mathrm{A}}^{2} /{\sigma^{2}}_{\mathrm{d}}$, em que: 
$\mathrm{K}_{1}$ : diferencial de seleção estandardizado, que depende da intensidade de seleção entre progênies = $10 \%(1,755)$;

$\mathrm{K}_{2}$ : diferencial de seleção estandardizado, que depende da intensidade de seleção dentro de progênies $=10 \%(1,755)$;

$\sigma_{\mathrm{d}}^{2}$ : variância fenotípica dentro de progênies de meios-irmãos.

Para o cálculo dos ganhos, considerou-se $\sigma_{\mathrm{d}}^{2}=10 \sigma^{2}$

\section{Resultados e Discussão}

Diferenças significativas $(\mathrm{P}<0,01)$, pelo teste $\mathrm{F}$, foram observadas entre as progênies do ciclo I dos dois materiais, o que evidencia a presença de variabilidade entre elas, bem como entre os locais (Tabela 1). A interação significativa progênies x locais revela o comportamento diferenciado entre as progênies, em face das oscilações ambientais. A importância da interação progênies x locais vem sendo detectada por diversos autores, com diversas populações, entre eles, Aguiar (1986) e Pacheco (1987), com ciclos original e I da população CMS 39, em três e dois locais, respectivamente, Carvalho et al. (2000a e 2000b), com progênies de meios-irmãos dos ciclos original, I e II das populações CMS 52 e CMS 453, respectivamente, e Carvalho et al. (2000c), com progênies de meios-irmãos dos ciclos II, III e IV da variedade BR 5033 Asa Branca. Os coeficientes de variação ambiental obtidos de 10,35\% (variedade sintética CMS 47) e 8,45\% (BR 5039) (Tabela 1) conferem boa precisão aos ensaios, conforme critérios adotados por Scapim et al. (1995). Para Paterniani (1968), a precisão dos ensaios é de grande importância, uma vez que, quanto mais precisas forem as médias das progênies avaliadas, melhor será a resposta e o progresso obtido com a seleção.

As produtividades médias obtidas nas progênies avaliadas e selecionadas da variedade sintética CMS 47 foram de $6.837 \mathrm{~kg} \mathrm{ha}^{-1} \mathrm{e} 8.113 \mathrm{~kg} \mathrm{ha}^{-1}$, respectivamente (Tabela 2 ). Essas médias corresponderam a $-18,0 \% \mathrm{e}-2,7 \%$ em relação à produtividade obtida com a variedade testemunha BR 5033 (Asa Branca). As progênies avaliadas e selecionadas da variedade BR 5039 produziram, respectivamente, $8.513 \mathrm{~kg} \mathrm{ha}^{-1}$ e $9.879 \mathrm{~kg} \mathrm{ha}^{-1}$ (Tabela 2), correspondendo a acréscimos de $2 \%$ e $18 \%$, em relação à variedade testemunha BR 106, o que

TABELA 1. Quadrados médios das análises de variância conjunta e coeficientes de variação nos ciclos I de seleção de progênies de meios-irmãos das variedades CMS 47 e BR 5039 (São Vicente). Região Meio-Norte do Brasil, 2000/2001.

\begin{tabular}{lccc}
\hline \multirow{2}{*}{ Fonte de variação } & Graus de liberdade & \multicolumn{2}{c}{ Quadrados médios } \\
\cline { 3 - 4 } & & CMS 47 & BR 5039 \\
\hline Progênies & 195 & $888,57 * *$ & $1225,58 * *$ \\
Progênies x locais & 195 & $722,66^{* *}$ & $1194,26 * *$ \\
Erro médio & 390 & 205,37 & 237,45 \\
\hline Média $\left(\mathrm{kg} \mathrm{ha}^{-1}\right)$ & & $6.837,00$ & $8.513,00$ \\
Média $\left(\mathrm{g} \mathrm{pl}^{-1}\right)$ & 138,33 & 180,64 \\
C. V. $(\%)$ & 10,35 & 8,45 \\
\hline
\end{tabular}

** Significativo a $1 \%$ de probabilidade, pelo teste $\mathrm{F}$. 
mostrou um alto potencial para a produtividade da variedade BR 5039, o que demonstra a possibilidade de sucesso na seleção.

Comparando-se os resultados obtidos por Cardoso et al. (2001), para o ciclo original de cada uma dessas cultivares, observa-se que houve uma forte redução da variabilidade genética desse ciclo inicial de seleção para o ciclo I (Tabela 3). Essa tendência vem sendo observada por diversos outros autores (Webel \& Lonquist, 1967; Paterniani, 1968; Pacheco, 1987; Santos \& Naspolini Filho, 1986a e Carvalho et al., 2000a, 2000b e 2000c) e ressaltada por Ramalho (1977) como sendo devido à utilização máxima da variabilidade livre existente no ciclo original e que responde à segregação entre blocos poligênicos. A partir do primeiro ciclo, é utilizada a variabilidade genética latente, presente dentro de blocos poligênicos e que vai sendo liberada gradativamente através da permuta genética.

As magnitudes das estimativas dos parâmetros genéticos foram mais expressivas na variedade sintética CMS 47 (Tabela 3), evidenciando maior variabilidade genética nesse material, quando comparado com a variedade BR 5039. Estimativas obtidas neste trabalho, com a variedade sintética
CMS 47, são contrastantes com as estimativas obtidas em diversas populações de milho brasileiras (Ramalho, 1977; Aguiar, 1986; Pacheco, 1987; Santos \& Naspolini Filho, 1986a e Carvalho et al.,1994 e 1998) e retratam a variabilidade genética presente nesse material. Segundo Paterniani (1968), é do máximo interesse que a variância aditiva permaneça tão alta quanto possível, para permitir a obtenção de progressos significativos por seleção. De acordo com o referido autor, o método de seleção entre e dentro de progênies meios-irmãos reduz muito essa variância, sobretudo no primeiro ciclo de seleção. As reduções observadas nas estimativas dessas variâncias no ciclo I já eram esperadas, em razão não só de exploração da variabilidade livre no ciclo original, conforme discutido, mas também por serem as progênies desse ciclo de seleção avaliadas em dois locais, tornando as estimativas menos influenciadas pelo comportamento da interação progênies x local.

As estimativas da variância da interação progênies x local mostram grande divergência entre os locais e um comportamento diferenciado das progênies nesses locais. Segundo Hallauer \& Miranda Filho (1988), esse componente da variância pode

TABELA 2. Produtividade média das progênies de meios-irmãos do ciclo I avaliadas e selecionadas e das testemunhas Asa Branca e BR 106. Região Meio-Norte do Brasil, 2000/2001.

\begin{tabular}{llccc}
\hline Ciclo & Material & $\begin{array}{c}\text { Produtividade } \\
\text { média } \mathbf{( k g ~ h a ~}^{-1} \text { ) }\end{array}$ & $\begin{array}{c}\text { Porcentagem em relação } \\
\text { às testemunhas }\end{array}$ \\
\hline I & CMS 47 & Progênies avaliadas & 6.837 & 82,0 \\
& & Progênies selecionadas (20) & 8.113 & 97,3 \\
& & Variação & 4.734 a 8.444 & 100,0 \\
\hline I & Asa Branca & 8.340 & 101,7 \\
& BR 5039 & Progênies avaliadas & 8.513 & 118,0 \\
& & Progênies selecionadas (20) & 9.879 & 100,0 \\
\hline
\end{tabular}


atingir mais de 50\% das estimativas da variância genética entre progênies e as estimativas dos parâmetros genéticos e fenótipicos obtidos em apenas um local são superestimadas, pela existência do componente da variação resultante da interação progênies x local, que não pode ser isolado.

Os coeficientes de herdabilidade no sentido restrito, com médias de progênies de meios-irmãos $\left(h^{2} \mathrm{~m}\right)$, superaram os obtidos nas próprias plantas $\left(h_{i}^{2}\right)$, nas duas cultivares, o que indica que a seleção com média de progênies deve ser mais eficiente que a seleção massal (Tabela 3). Segundo Ramalho (1977), estimativas de herdabilidade ao nível de médias de progênies são normalmente obtidas em experimentos de seleção. Todavia, conforme relata o autor, os valores obtidos são difíceis de serem comparados, em razão de, nesses trabalhos, se utilizarem números diferentes de repetições, ambientes, anos e tipos de progênies nas unidades de seleção. Por outro lado, a herdabilidade ao nível de plantas é compatível com um número maior de situações, conforme argumenta Ramalho (1977). As estimativas obtidas dos coeficientes de variação genético e dos índices $b$ refletem pouca variação entre as progênies do ciclo I das cultivares estudadas, sendo essa variação bem menor entre as progênies da variedade BR 5039 (Tabela 3). Os valores encontrados com a variedade CMS 47 foram da mesma magnitude daqueles relatados por Carvalho et al. (1998 e 2000a), com progênies do ciclo I das cultivares BR 5028 (São Francisco) e CMS 52, também na média de dois locais. Vale ressaltar que, na literatura, diversas estimativas dos coeficientes de variação genética e dos índices b oscilaram de 2,10\% a $15,31 \%$ e 0,10 a 0,88, respectivamente (Ramalho, 1977; Santos, 1985; Pacheco, 1987 e Carvalho et al., 1994). Os autores mencionados consideraram as populações como potencialmente promissoras, tendo em vista a quantidade de variabilidade genética que foi exibida.

TABELA 3. Estimativas ${ }^{1}$ dos parâmetros genéticos do caráter peso de espigas (g planta $\left.{ }^{-1}\right)^{2}$ das variedade sintética CMS 47 e da variedade BR 5039. Região Meio-Norte do Brasil, 2000/2001.

\begin{tabular}{lcc}
\hline Estimativas & CMS 47 & BR 5039 \\
\hline$\sigma_{\mathrm{p}}^{2}\left(\mathrm{~g} \mathrm{pl}^{-1}\right)^{2}$ & 41,48 & 7,83 \\
$\sigma_{\mathrm{A}}^{2}\left(\mathrm{~g} \mathrm{pl}^{-1}\right)^{2}$ & 165,92 & 31,32 \\
$\sigma_{\mathrm{pxl}}^{2}\left(\mathrm{~g} \mathrm{pl}^{-1}\right)^{2}$ & 258,64 & 478,41 \\
$\mathrm{~h}_{\mathrm{m}}^{2}$ & 18,67 & 2,56 \\
$\mathrm{~h}^{2}$ & 8,98 & 1,40 \\
$\mathrm{C} . \mathrm{V}_{\mathrm{g}}(\%)$ & 4,65 & 1,54 \\
$\mathrm{~b}$ & 0,45 & 0,18 \\
$\mathrm{Gs}$ entre $\left(\mathrm{g} \mathrm{pl}{ }^{-1}\right)$ & 4,88 & 0,78 \\
$\mathrm{Gs}$ entre $(\%)$ & 3,53 & 0,43 \\
Gs dentro $\left(\mathrm{g} \mathrm{pl}^{-1}\right)$ & 2,91 & 0,52 \\
Gs dentro $(\%)$ & 2,10 & 0,29 \\
Gs total & 5,63 & 0,72 \\
\hline
\end{tabular}

$\sigma_{\mathrm{p}}^{2}$ : variância genética entre progênies; $\sigma_{\mathrm{A}}^{2}$ :variância genética aditiva;

$\sigma_{\mathrm{pxl}}^{2}$ : variância da interação progênies x locais; $\mathrm{h}_{\mathrm{m}}^{2}$ : coeficiente de herdabilidade no sentido restrito ao nível de médias de progênies; $h^{2}$ : coeficiente de herdabilidade no sentido restrito ao nível de planta; C.Vg: coeficiente de variação genético; b: índice de variação; Gs: ganhos entre e dentro de progênies de meios-irmãos; Gs: ganho total por ciclo / ano. 
Os ganhos estimados com a seleção entre e dentro de progênies de meios-irmãos foram de $3,53 \%$ e $2,10 \%$, totalizando $5,63 \%$, com a variedade sintética CMS 47 e, $0,43 \%$ e $0,29 \%$, totalizando $0,72 \%$, com a variedade BR 5039 . Os valores obtidos com progênies da variedade sintética CMS 47 foram de magnitudes semelhantes aos encontrados por Santos \& Naspolini Filho (1986) e Carvalho et al. (1998 e 2000a), o que expressa, mais uma vez, o potencial genético dessa população em responder à seleção com vistas ao aumento da produtividade de espigas.

Deve-se salientar que um ciclo de seleção entre e dentro de progênies de meios-irmãos, com sementes remanescentes, foi completado em um ano, com os dois materiais, na condição do presente trabalho, em razão de as progênies serem avaliadas sob regime de sequeiro, na época do período chuvoso, e as recombinações serem realizadas no período da seca, com irrigação. Na literatura, diversos trabalhos têm relatado ganhos genéticos esperados com a seleção entre e dentro de progênies de meios-irmãos, sendo, porém, um ciclo completado em dois anos (Webel \& Lonquist, 1967; Paterniani,1968; Compton \& Bahadur, 1977; Aguilar Moran, 1984). Os resultados encontrados com a variedade sintética CMS 47 foram superiores quando comparados com aqueles encontrados pelos autores acima mencionados, quando são feitas comparações de um ano para dois anos, e o fato também de as estimativas serem obtidas na média de dois locais, estando, assim, menos influenciadas pala interação progênies $\mathrm{X}$ locais.

\section{Conclusões}

A variedade sintética CMS 47, por apresentar alta variabilidade genética e ser de ciclo superprecoce, constitui-se em excelente alternativa para a obtenção de uma cultivar melhor adaptada para as áreas de domínio do semi-árido nordestino, a curto prazo.
As estimativas das variâncias genéticas entre progênies evidenciam a importância de se realizar a seleção em mais de um local, para melhorar a adaptação das cultivares, a eficiência do processo seletivo e permitir a obtenção de estimativas dos componentes da variância pouco influenciados pela interação progênies x locais.

A variedade BR 5039 pode ser aproveitada para uso imediato no região, por apresentar ótima adaptação.

\section{Literatura Citada}

AGUIAR, P. A. Avaliação de progênies de meios-irmãos de milho CMS 39 em diferentes condições de ambientes. 1986. 86 f. Dissertação (Mestrado) - Escola Superior de Agricultura de Lavras, Lavras.

AGUILLAR MORAN, J. F. Avaliação do potencial de linhagens e respectivos testadores obtidas de duas populações de milho (Zea mays L.) 1984. 118 f. Dissertação (Mestrado) - Escola Superior de Agricultura 'Luiz de Queiroz", Universidade de São Paulo, Piracicaba.

BIGOTO, C. A. Estudo da população ESALQPB I de milho (Zea mays $\mathrm{L}$ )em cinco ciclos de seleção recorrente. 1988. 122 f. Dissertação (Mestrado) - Escola Superior de Agricultura "Luiz de Queiroz", Universidade de São Paulo, Piracicaba.

CARDOSO, M. J.; CARVALHO, H. W. L. de.; LEAL, M. de L da S.; SANTOS, M. X. dos. Estimativas de parâmetros genéticos na variedades de milho CMS 47 e BR 5039. Revista Científica Rural, Bagé, v. 6, n. 2, p. 153 - 160, 2001.

CARDOSO, M. J.; CARVALHO, H. W. L. de.; PACHECO, C. A. P. SANTOS, M X. dos.; LEAL, M. de L da S. Adaptabilidade e estabilidade de cultivares de milho no Estado do Piauí, no biênio 1993/ 1994. Revista Científica Rural, Bagé, v. 2, n. 1, p. 35 - 44, 1997. 
CARVALHO, H. W. L de.; GUIMARÃES, P. E. de O.; LEAL, M. de L da S.; CARVALHO, P. C. L. de.; SANTOS, M. X. dos. Avaliação de progênies de meios-irmãos da população de milho CMS 453 no Nordeste brasileiro. Pesquisa Agropecuária Brasileira, Brasília, v. 35, n. 8, p. 1577 - 1584, 2000b.

CARVALHO, H. W. L de.; LEAL, M. de L da S.; GUIMARÃES, P. E. de O.; SANTOS, M. X. dos.; CARVALHO, P. C. L. de. Três ciclos de seleção entre e dentro de progênies de meios-irmãos na população de milho CMS 52. Pesquisa Agropecuária Brasileira, Brasília, v. 35, n. 8, p. 1621 - 1628, 2000a.

CARVALHO, H. W. L de.; PACHECO, C. A P.; SANTOS, M. X. dos.; GAMA, E. E. G.; MAGNAVACA, R. Três ciclos de seleção entre e dentro de famílias de meios-irmãos na população de milho BR 5011 no Nordeste brasileiro. Pesquisa Agropecuária Brasileira, Brasília, v. 35, n. 5, p. $713-720,1998$.

CARVALHO, H. W. L de.; PACHECO, C. A P.; SANTOS, M. X. dos.; GAMA, E. E. G.; MAGNAVACA, R. Três ciclos de seleção entre e dentro de progênies de meios-irmãos na população de milho BR 5028 - São Francisco no Nordeste brasileiro. Pesquisa Agropecuária Brasileira, Brasília, v. 29, n. 11, p. 1727 - 1733, 1994.

CARVALHO, H. W. L de.; SANTOS, M. X. dos.; LEAL, M. de L da S.; CARAVLHO, P. C. L. de. Melhoramento genético da cultivar de milho BR 5033-Asa Branca no Nordeste brasileiro. Pesquisa Agropecuária Brasileira, Brasília, v. 35, n. 7, p. $1417-1425,2000$ c.

COMPTON, W. A.; BAHADUR, K. Tem cycles of progrss from modified ear-to-row selection in corn. Crop Science, Madison, v. 17, p. 378 - 380, 1977.
HALLAUER, A. R.; MIRANDA FILHO, J. B. Quantitative genetics in maize breeding. 2. ed. Ames: Iowa State University Press, 1988. 468 p.

PACHECO, C. A. P. Avaliação de progênies de meios -irmãos na população de milho CMS 39 em diferentes condições de ambiente - $2^{\circ}$ de seleção. 1987. 109 f. Dissertação (Mestrado) Escola Superior de Agricultura de Lavras, Lavras.

PATERNIANI, E. Avaliação de métodos de seleção entre e dentro de famílias de meios-irmãos no melhoramento de milho (Zea mays L). 1968. 92 f. Dissertação (Mestrado) - Escola Superior de Agricultura “Luiz de Queiroz", Universidade de São Paulo, Piracicaba.

RAMALHO, M. A. P. Eficiência relativa de alguns processos de seleção intrapopulacional no milho baseados em famílias não endógamas. 1977. 122 f. Dissertação (Mestrado) - Escola Superior de Agricultura “Luiz de Queiroz”, Universidade de São Paulo, Piracicaba.

SANTOS, M. X dos. Estudo do potencial de duas raças brasileiras de milho (Zea mays $\mathrm{L}$ ) para fins de melhoramento. 1985. $186 \mathrm{f}$. Tese (Doutorado) - Escola Superior de Agricultura "Luiz de Queiroz”, Universidade de São Paulo, Piracicaba.

SANTOS, M. X dos.; NASPOLINI FILHO. W. Estimativas de parâmetros genéticos em três ciclos de seleção entre e dentro de progênies de meiosirmãos no milho (Zea mays L.) Dentado Composto Nordeste. Revista Brasileira de Genética , Ribeirão Preto, v. 9, n. 2, p. 307 - 3019, 1986a.

SCAPIM, C. A.; CARVALHO, C. G. P.; CRUZ, C. D. Uma proposta de classificação dos coeficientes de variação para a cultura do milho. Pesquisa Agropecuária Brasileira, Brasília, v. 30, n. 5, p. $683-686,1995$. 
VENCOVSKY, R. Herança quantitativa . In: WEBEL, O. D.; LONQUIST, J.H. Na evalution of PATERNIANI, E. (Ed.).Melhoramento e produ- modified ear-to-row selection in a population of corn ção do milho no Brasil. Piracicaba: ESALQ, 1978. (Zea mays L.). Crop Science, Madison, v. 7, p. p. $122-201$. $651-655,1967$.

VENCOVSKY, R.; BARRIGA, P. Genética

biométrica no fitomelhoramento. Ribeirão Preto:

Sociedade Brasileira de Genética, 1992. 496 p. 